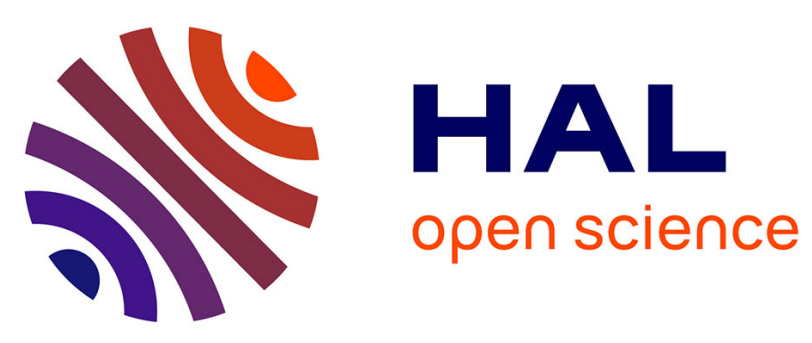

\title{
High efficiency UWB pulse generator for ultra-low-power applications
}

Remy Vauche, Sylvain Bourdel, Nicolas Dehaese, Jean Gaubert, Oswaldo Ramos Sparrow, Eloi Muhr, Herve Barthelemy

\section{To cite this version:}

Remy Vauche, Sylvain Bourdel, Nicolas Dehaese, Jean Gaubert, Oswaldo Ramos Sparrow, et al.. High efficiency UWB pulse generator for ultra-low-power applications. International Journal of Microwave and Wireless Technologies, 2016, 8 (3, SI), pp.495-503. 10.1017/S1759078715000355 . hal-01435274

\section{HAL Id: hal-01435274 \\ https://hal.science/hal-01435274}

Submitted on 23 May 2018

HAL is a multi-disciplinary open access archive for the deposit and dissemination of scientific research documents, whether they are published or not. The documents may come from teaching and research institutions in France or abroad, or from public or private research centers.
L'archive ouverte pluridisciplinaire $\mathbf{H A L}$, est destinée au dépôt et à la diffusion de documents scientifiques de niveau recherche, publiés ou non, émanant des établissements d'enseignement et de recherche français ou étrangers, des laboratoires publics ou privés. 


\section{High Efficiency UWB Pulse Generator for Ultra Low Power Applications}

Remy Vauche ${ }^{1}$, Sylvain Bourdel ${ }^{2,3}$, Nicolas Dehaese ${ }^{1}$, Jean Gaubert ${ }^{1}$, Oswaldo Ramos Sparrow $^{1}$, Eloi Muhr ${ }^{1}$, Herve Barthelemy ${ }^{1}$

${ }^{1}$ Aix Marseille Université, CNRS, Université de Toulon, IM2NP UMR 7334 Marseille, France

${ }^{2}$ Univ. Grenoble Alpes, IMEP-LAHC, F-38000 Grenoble, France

${ }^{3}$ CNRS, IMEP-LAHC, F-38000 Grenoble, France

This paper presents the design of a fully integrated ultra low power Ultra Wide Band (UWB) pulse generator. The circuit is designed and optimized for low rate and localization applications. This UWB transmitter is based on the impulse response filter method in order to achieve high energy sub-nanosecond pulses. The circuit has been integrated in a ST-Microelectronics CMOS $0.13 \mu \mathrm{m}$ technology with a supply voltage of $1.2 \mathrm{~V}$ on a die area of $0.56 \mathrm{~mm}^{2}$. A power manager is used to reduce the power leakages to $3.91 \mu \mathrm{W}$ which gives a power consumption of $3.98 \mu \mathrm{W} @ 10 \mathrm{kbs}^{-1}$. The measured dynamic energy consumed per pulse is 68pJ and the measured energy of the emitted pulse is $2.15 p J$.

Keywords: Authors should not add keywords, as these will be chosen during the submission process (see http://journals.cambridge.org/data/relatedlink/MRF_topics.pdf for the full list)

Corresponding author: R. Vauche; email: remy.vauche@im2np.fr; phone: +33 650129265

\section{INTRODUCTION}

Thanks to the gated nature of the signal, Ultra Wide Band Impulse Radio (IR-UWB) is a promising technology for ultra low power application. When efficient power gating techniques are used, the power consumption between two consecutive pulses can be highly reduced and the overall power consumption is scalable with the bit rate. Consequently, IR-UWB is a good candidate for ultra low power applications such as Radio Frequency Identification (RFID), or autonomous Wireless Sensor Network (WSN) in particular when localization capabilities are needed. For these applications, the need for (low cost) self or remotely powered communication systems is very high.

The design of an ultra low power communication system is a very challenging issue, especially concerning the radio-frequency front-end which generally consumes the greatest part of the power budget. For example, in a remotely powered RFID UHF transmitters commonly named passive TAGs, the available power is only about few micro-watts at 10 meters from the reader and has to supply the TAG [1]. In the case of a $10 \mathrm{~cm}^{2}$ photovoltaic harvesting system, the available power is around $100 \mu \mathrm{W}$ under $100 \mathrm{~lm}$ (lumen) lighting which corresponds to a typical indoor environment. In both cases, the 
energy must be stored which is a major drawback. First, the use of an energy tank such as external capacitors or micro-battery (cell) increases the manufacturing cost. Second, the communication is turned off when the battery is charging which reduces the instantaneous bit rate. IR-UWB can resolve these issues since previous published works present fully integrated transmitters having a power consumption of few micro-watts [2]. Such power consumption allows the system to be always powered and lower than the constraint on the storage. Since it reduces the storage constraints and can be fully integrated, IR-UWB appears to be a good low cost solution for ultra low power applications.

Moreover, IR-UWB is also a promising technology for localization systems due to the high temporal resolution of the signal. Both localization and low cost are interesting properties for ultra low power applications such as RFID or WSN, but they need high energy pulses to be efficiently exploited. Indeed, high energy pulses increase the localization precision [3] and enable the use of a low cost non-coherent receiver [4]. Finally, to meet these application requirements, the transmitted energy must be increased while the energy consumed by pulse must be reduced. In other words, the energy efficiency of the transmitter must be increased as much as possible. Consequently, this energy efficiency appears to be the most significant Figure Of Merit (FOM) in order to evaluate performance in such a context.

In this paper, we present the design of an ultra low power pulse generator providing high energy pulses. The power consumption and the energy efficiency have been optimized for ultra low power and low cost systems. In the first part, starting from the analysis of the FOM presented in the literature dedicated to pulse generators, a design strategy which optimizes the energy efficiency for a given low power application is presented. Then the proposed architecture, based on an integrated filter excitation technique, is described in section III. Particular attention is paid to the power management and to the output dynamic. The last section presents measurement results of the pulse generator realized in a standard 130nm CMOS technology.

\section{POWER EFFICIENT TOPOLOGY}

\section{A) Figure of Merit}

For pulse generator design, the most often used FOM is the consumed energy per bit $E_{C}$ which is easily derived from the power measurement as follows:

$$
E_{C}=\frac{P_{D C} @ P R F}{P R F}
$$

where $P R F$ is the pulse repetition frequency and $P_{D C} @ P R F$ the power consumption measured at a given $P R F$. In a practical implementation, due to leakage or biasing, some energy is consumed between the emission of two consecutive pulses and $E_{C}$ varies with $P R F$ as shown in Fig. 1. It is therefore difficult to extrapolate from $E_{C}$, the power consumption at any $P R F$ and then to compare different architectures designed for different bit rates.

To overcome this limitation, [5] gives the power consumed at a $P R F$ equal to $0 \mathrm{~Hz}\left(P_{0 \mathrm{~Hz}}\right)$ which represents the leakage power and the energy dynamically consumed by the generator $\left(E_{A C}\right)$. As shown in Fig. 1, these metrics give the power consumption as a 


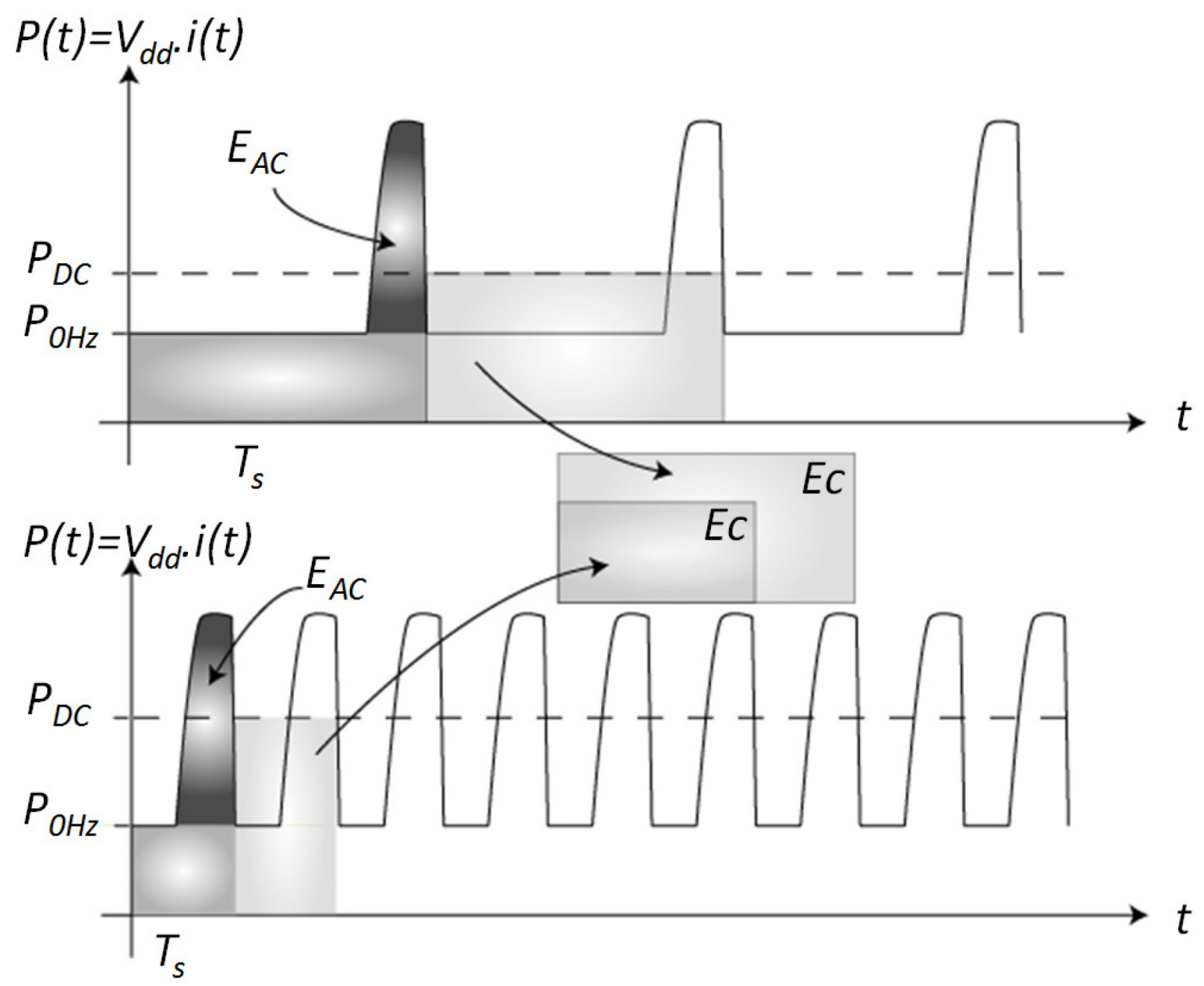

Figure 1: Instantaneous consumed power.

function of the $P R F$ as follows :

$$
P_{D C}(P R F)=P_{0 H z}+E_{A C} \cdot P R F
$$

These FOM are interesting since they give the power consumption at any bit rate.

Moreover, these FOM can be easily extracted from measurements since $P_{D C}$ linearly varies with $P R F$.

However, this FOM has some limitations. Since it does not take the emitted power $P_{E}$ into account, it is not possible to compare pulse generators that produce pulses with different energies. It is then relevant to evaluate the power efficiency which is finally equal to the energy efficiency shown as follows :

$$
\eta(P R F)=\frac{P_{E}}{P_{D C}}=\frac{E_{P} \cdot P R F}{E_{C} \cdot P R F}=\frac{E_{P}}{P_{0 H z} / P R F+E_{A C}}
$$

where $E_{P}$ is the energy of the emitted pulse. This FOM can also be obtained from measurement data $\left(E_{P}=P_{E} / P R F\right)$. Due to the frequency limitation of some topologies, $E_{P}$ can decrease with the $P R F$. This FOM enables this effect to be taken into account. 


\section{B) Design strategies}

Fig. 2 presents the power consumption of different published pulse generators. [5] and [6] principally use CMOS digital circuits which have no DC power consumption. This leads to a low $P_{0 H z}$ which is mainly due to leakage current $(96 \mu \mathrm{W}$ and $5 \mu \mathrm{W}$ for [5] and [6] respectively). It appears that a low $P_{0 \mathrm{~Hz}}$ performs best at low rate and leakage is one of the main issues in this context. In [7], differential MOS Current Mode Logic cells are used. This gives a high DC power consumption $(3.2 \mathrm{~mW} @ 0 \mathrm{~Hz})$ and a small $E_{A C}$ (6.4pJ/pulse) compared to other works (47 and 30pJ/Pulse for [5] and [6] respectively) since differential structures do not consume dynamic current. Fig. 2 clearly shows that this topology performs better for $P R F$ higher than $100 \mathrm{MHz}$ and that reducing $E_{A C}$ is the main issue for the design of high speed pulse generators.

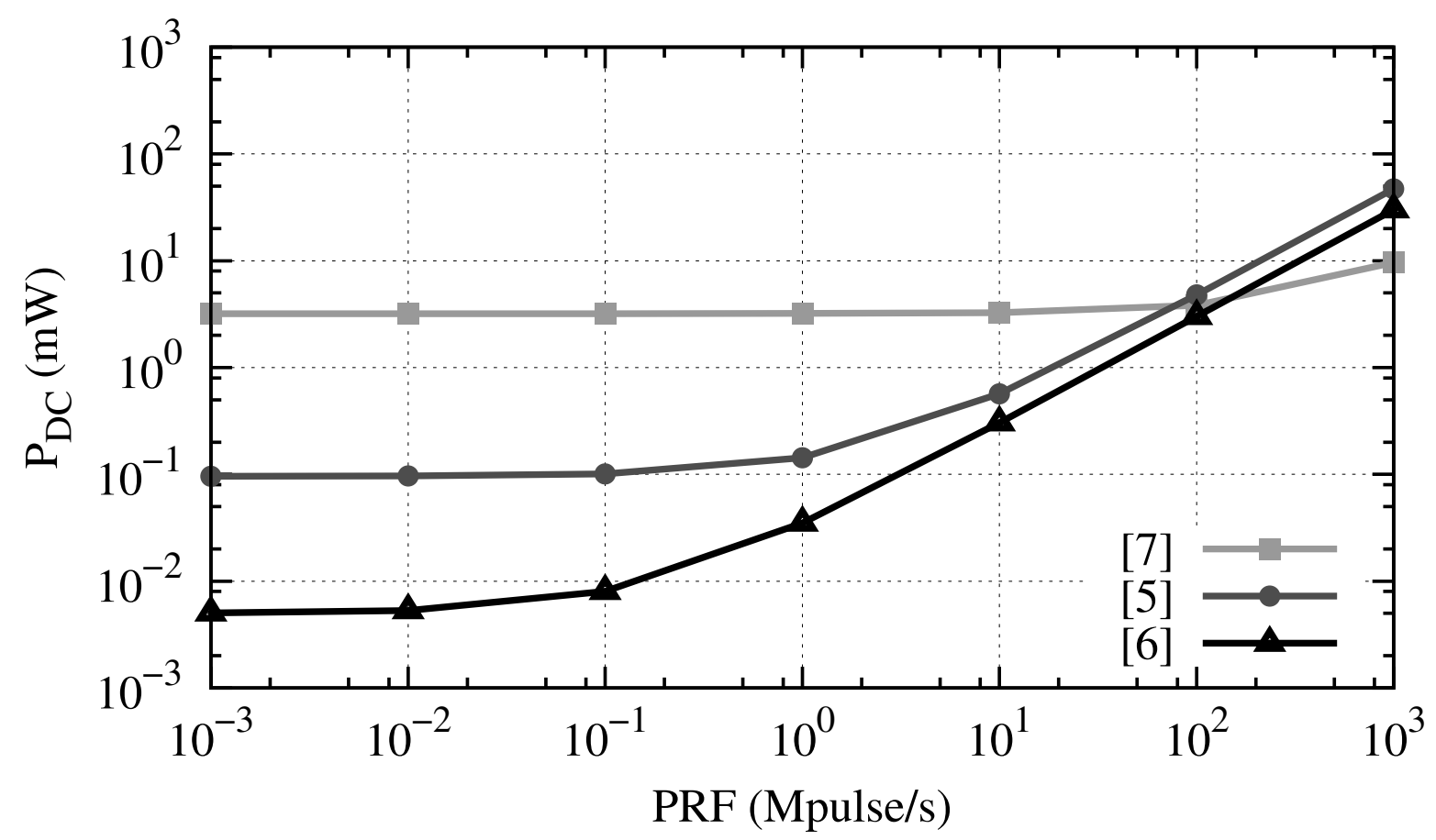

Figure 2: Power consumption of several published pulse generators.

The efficiency is given by (3) and shows relevant information. In Fig. 3 the efficiency is plotted as a function of the bit rate for the same generators as in Fig. 2. Since $E_{P}$ is rarely given, it has been approximated using (6) and (7). For a better approximation, the effect of the pulse envelope on the energy is taken into account. Depending on the pulse shape, the pulse is modeled by a sine wave modulated by square function (4) or by a Gaussian pulse transposed at the center frequency $f_{M}$ of the pulse (5).

$$
\begin{gathered}
p_{S}(t)=A \sin \left(2 \pi f_{M} t\right) \pi_{\tau}(t) \\
p_{G}(t)=A \exp \left(-a t^{2}\right) \cos \left(2 \pi f_{M} t\right)
\end{gathered}
$$

The energy of the pulse can then be easily derived from the maximum value of the pulse $A$ and its width $\tau$ as follows: 


$$
\begin{gathered}
E_{P S}=\frac{A^{2}}{Z_{L}}\left[\frac{\tau}{2}-\frac{\sin \left(2 \pi f_{M} \tau\right)}{4 \pi f_{M}}\right] \\
E_{P G}=\frac{A^{2}}{2 Z_{L}} \sqrt{\frac{\pi}{2 a}}\left[1+\exp \left(-\frac{\left|4 \pi f_{M}\right|^{2}}{8 a}\right)\right] \text { with } a=\frac{\pi^{2} B W_{-X d B}^{2}}{2 \ln \left(10^{X d B / 10}\right)}
\end{gathered}
$$

where $Z_{L}$ is the load impedance of the pulse generator and $B W_{-X d B}$ the $-X d B$ bandwidth. An analysis of the efficiency gives interesting information for the design strategies. [5] achieves a higher output dynamic $A$ than [6] which consequently increases the dynamic consumed energy $E_{A C}$. It is a drawback when only the power consumption is considered but, as shown in Fig. 3, the efficiency is finally higher for bit rates higher than a few MHz. It also appears that maximizing the output dynamic is an important issue when high efficiency is needed, even if it is at the cost of an increased $E_{A C}$.

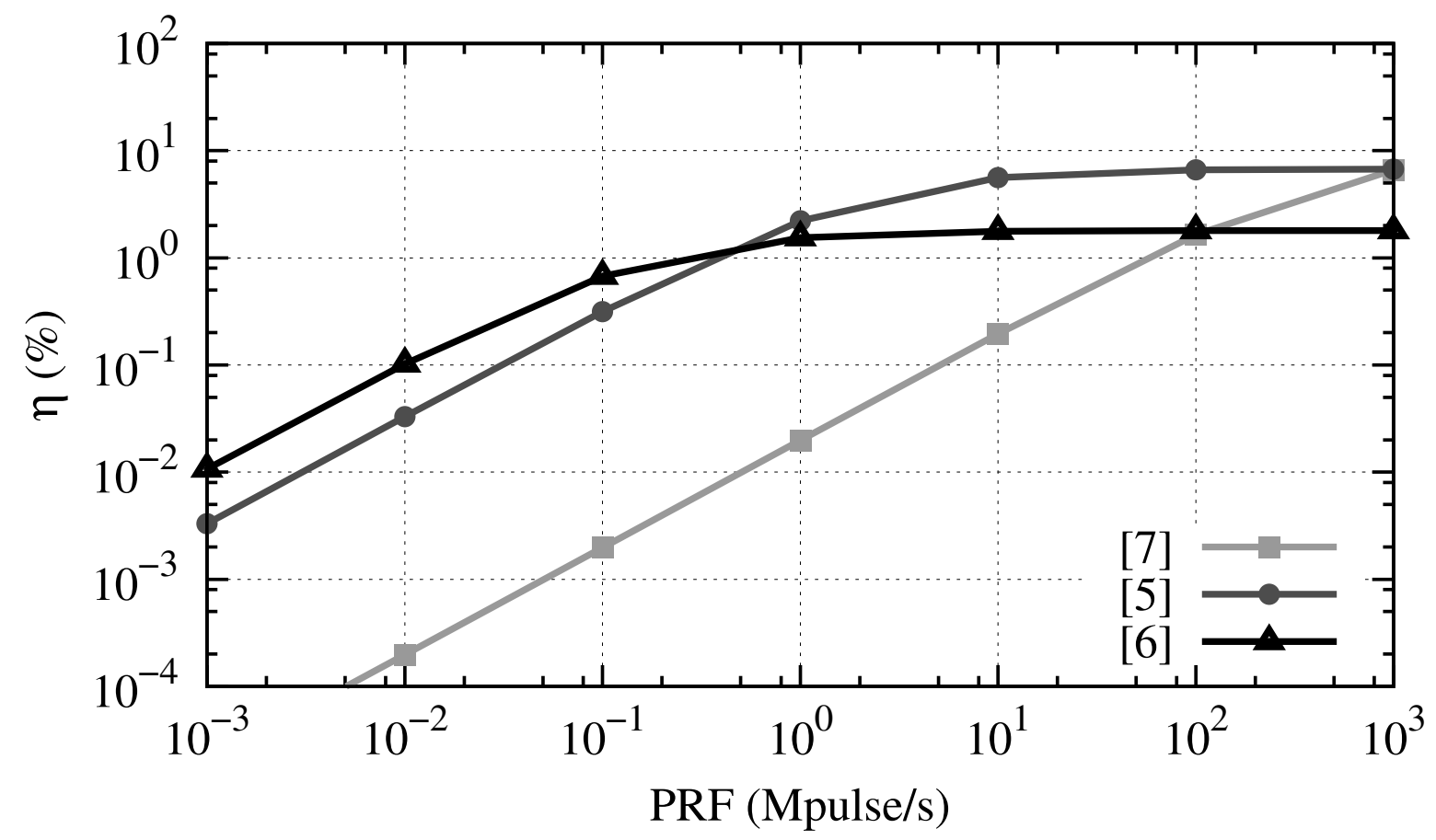

Figure 3: Energy efficiency of several published pulse generators.

Based on these observations, the presented design will first focus on leakage current reduction methods to address ultra low power and low rate applications. Secondly, the output dynamic will be maximized (at the cost of an increased $E_{A C}$ ) to improve the efficiency and also to optimize the power budget which is an important issue in low power applications.

\section{C) Architecture Choice}

Among the different techniques used for pulse generation, ON/OFF Local Oscillator (LO) and filter excitation are the most promising topologies to reduce power consumption. To 
maximize the output dynamic and the bandwidth in ON/OFF LO, the LO start time must be as small as possible and an inverter based ring oscillator should be preferred [8]. With such topology, CMOS technology can be used which reduces the $P_{0 H z}$. ON/OFF LO technique highly reduces the $P_{0 \mathrm{~Hz}}$ since the LO is turned on only during the pulse duration. To be fully efficient, the power amplifier or the antenna driver must be power managed $[9,10]$. To reduce further the time conduction of the active cells, it is possible to use filter excitation. With such a technique, a very short baseband pulse is used to excite a filter to produce its impulse response. Here, the conduction time of the active cells is around 100ps [7] and is independent of the pulse bandwidth $B W$ whereas in ON/OFF LO it depends on $1 / B W$. A short time conduction of the active cells limits $E_{A C}$ and improves the efficiency. Moreover, the filter excitation technique can achieve large amplitude pulses which lead to high $E_{P}$. It also facilitates the integration and the packaging process [11]. At last, the filter excitation well suits the generation of sub-nanosecond duration pulses needed to reach high localization precision [7].

The proposed architecture is based on an integrated filter excitation technique and the principle is given in Fig. 4. The baseband pulse used to excite the filter is generated by a Low-Vt Digital Edge Combiner implemented with CMOS logic cells. To reduce the leakages, a high-Vt Managed Power Supply (MPS) which control managed power lines (V-VDDX and V-GNDX) is used. The filter is a passive fully integrated circuit and is driven by a $\mathrm{C}$ class amplifier to reduce $P_{\mathrm{OHz}}$ consumption.

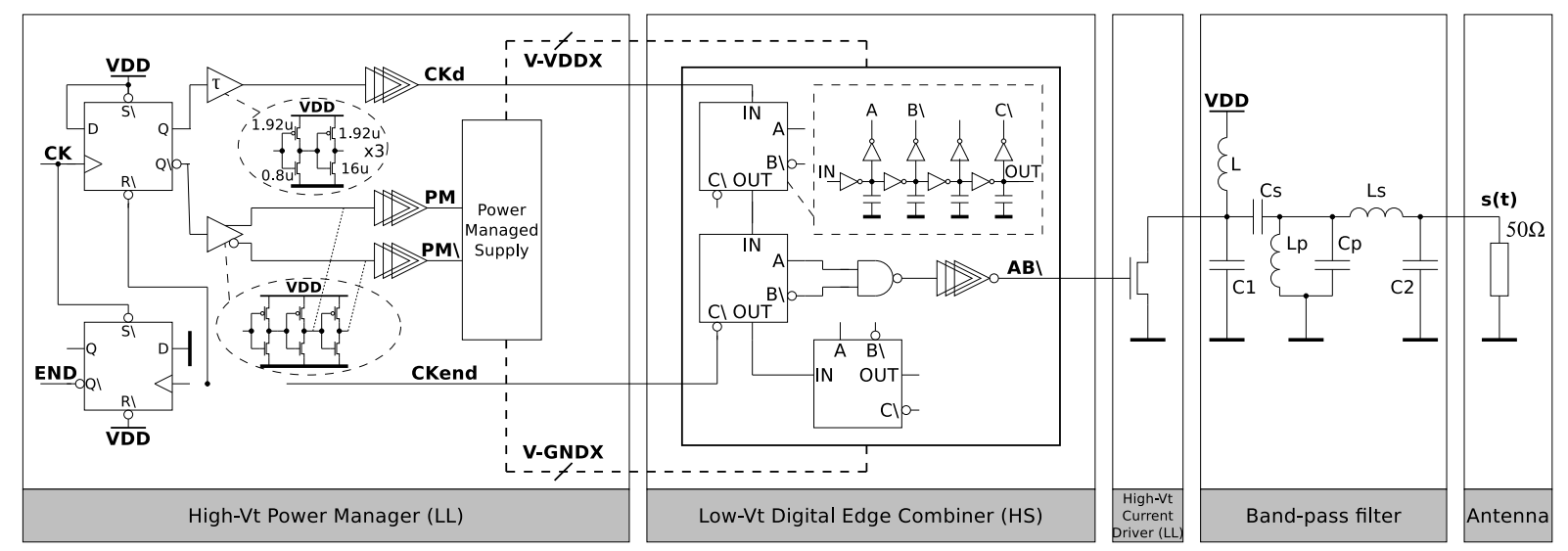

Figure 4: Proposed pulse generator principle.

\section{PULSE GENERATOR DESIGN}

The pulse $s(t)$ produced by the excitation filter technique is the response of the filter to a baseband pulse $\pi_{\tau}(t)$. The expression of $s(t)$ and its Fourier transform are given by :

$$
\begin{gathered}
s(t)=\frac{B}{\sqrt{l}} \cdot \pi_{\tau}(t) * h_{E}(t) \\
S(f)=\frac{B \tau \operatorname{sinc}(\pi \tau f) \cdot H_{E}(f)}{\sqrt{l}}
\end{gathered}
$$


where $l$ represents the power loss of the filter, $H_{E}(f)$ the normalized transfer function of the filter, $B$ the magnitude of the basesband pulse and $\tau$ its time duration. The main characteristics of the pulse are given by the baseband pulse (through $B$ and $\tau$ ) and by the filter impulse response. This technique has been widely presented and a detailed sizing method is given in [7]. In this design, we use a third order Bessel-Thompson filter driven by a $1.2 \mathrm{~V}$ magnitude and $75 \mathrm{ps}$ width baseband pulse. A standard CMOS 130nm technology is used.

\section{A) Power Management System}

The aim of the power manager is to reduce the leakage current when no pulses are generated. Several techniques have been proposed to reduce leakage current of CMOS logic circuits. A first technique named VTCMOS consists in applying different bias voltages to the substrate depending on the operating mode of the cell [12]. When the cell is off, the substrates of the NMOS transistor (resp. PMOS) can be for example connected to VDD (resp. GND) in order to increase (resp. decrease) the threshold voltage $V t$ and thus limiting the leakages. A second technique (DTCMOS) consists in dynamically changing the threshold voltage when the circuit is commuted [13]. In the CMOS inverter case, the gates of the PMOS and NMOS are connected to the substrate. For both VTCMOS and DTCMOS, an isolated substrate is needed and triple-well or SOI technologies must be used which increase the manufacturing cost. A third solution is to use a multi-Vt CMOS technology [14] which provides transistors having different threshold voltages. Most of the standard CMOS technologies offer Low Leakage (LL) transistors having high-Vt and High Speed (HS) transistors having low $V t$. The proposed power manager uses a multi-Vt-CMOS approach where Low Leakage (LL) transistors are used to power supply the High Speed (HS) transistors which are used to implement the Low-Vt Digital Edge Combiner.

The elementary inverter used in the design of the Digital Edge Combiner is presented in Fig. 5. The NMOS and PMOS HS transistors have respectively their bulks connected to GND and VDD whereas their sources are respectively connected to the managed power line V-GNDX and V-VDDX provided by the MPS. The MPS is based on LL inverters which are sized in order to deliver the same drain source current $I_{D S}$ than the HS transistors. Since $I_{D S}$ is a linear function of the saturation current density $J_{S A T}$ (A.m-1) and of the MOS width $W[15]$, the required size of the LL is given by :

$$
W_{L L}=\frac{J_{S A T-H S}}{J_{S A T-L L}} \cdot W_{H S}
$$

where the NMOS, or the PMOS transistors of the HS and LL inverters can be considered. The idle state of the HS inverter output defines the signal to be connected at the input of the LL inverter of the MPS. When the idle state is 0 , the LL inverter input which provides V-GNDX is connected to VDD and the LL inverter input which provides $\mathrm{V}$-VDDX is connected to PM since it is the power management signal active on the high state provided by MPS. When the idle state is 1, the LL inverter input which provides V-GNDX is connected to PM $\backslash$ and V-VDDX is connected to GND. Thus, when power management is active $(\mathrm{PM}=1)$, HS inverter is short-circuited since its V-GNDX, $\mathrm{V}$-VDDX and also OUT are equal to the same voltage. In this case, the total leakage 
depends only on twice the sum of leakage current of the LL inverter which is much lower than the HS inverter leakage for an equivalent saturated current. The gain $g_{O F F}$ on the leakage power $P_{0 \mathrm{~Hz}}$ achieved by this power management technic only depends on the saturation current density $J_{S A T}$ of the LL and HS transistor and is given by :

$$
g_{O F F}=\frac{J_{O F F-H S} \cdot W_{H S}}{2 \cdot J_{O F F-L L} \cdot W_{L L}}=\frac{J_{O F F-H S} \cdot J_{S A T-L L}}{2 \cdot J_{O F F-L L} \cdot J_{S A T-H S}}
$$

where $J_{O F F}$ is the linear leakage current density $\left(\mathrm{A} \cdot \mathrm{m}^{-1}\right)$ of the considered MOS transistor. It clearly appears that the proposed power management technic has benefits only when the ratio between $J_{S A T}$ and $J_{O F F}$ of the LL inverters is greater than twice the one of the HS.

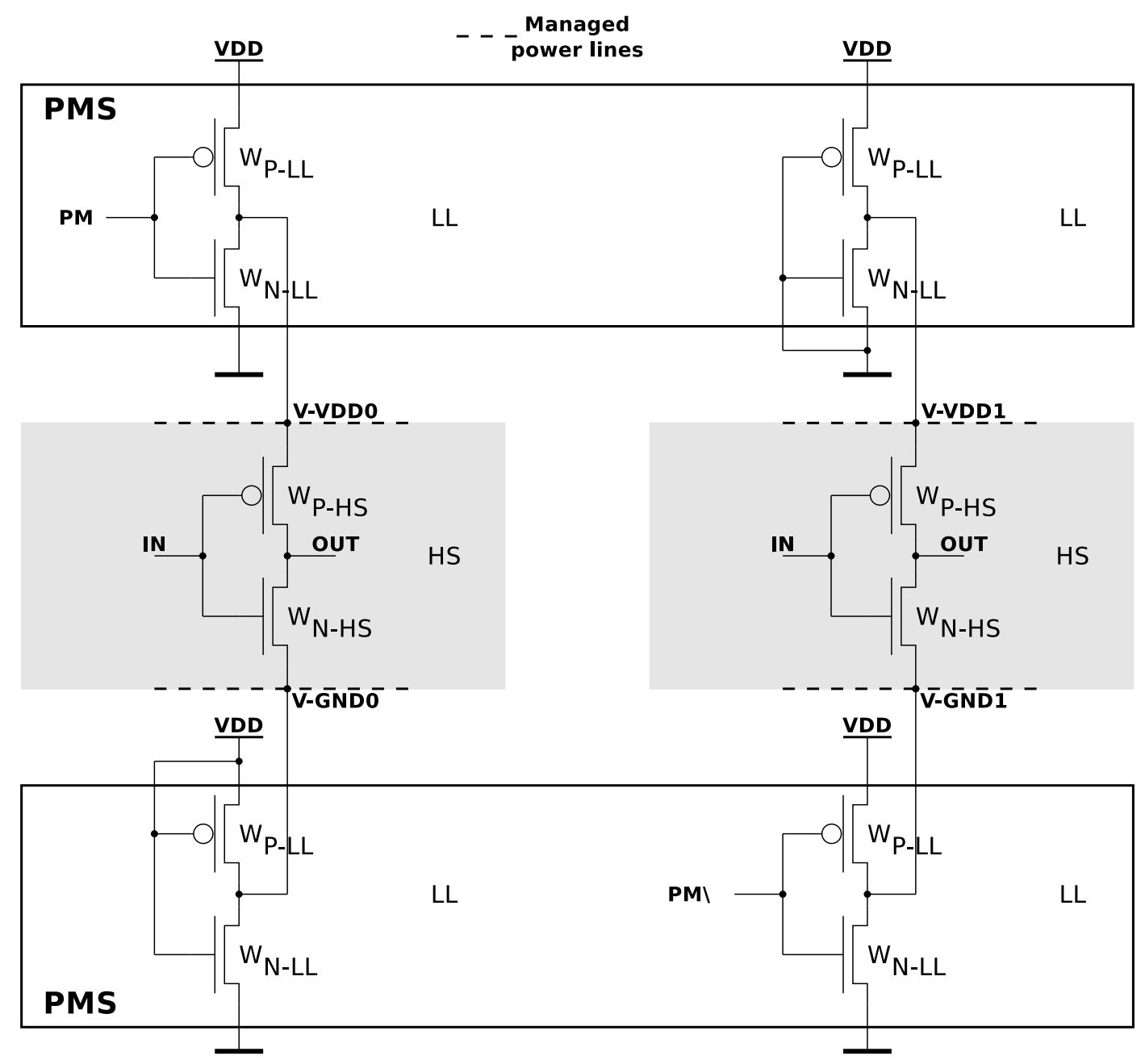

(a)

(b)

Figure 5: Inverter set to 0 (a) and set to 1 (b) in the idle state with its associated Managed Power Supply (MPS). 
In the case of a more complex logic function such as the inverter chains used in the edge combiner or in the power manager, a particular focus has to be done on the chosen idle state of each stage which composes the function. Here the idle states have to be alternatively 0 and 1 in order to keep coherent logic states with the realized logic function inside each HS stage as shown on Fig. 6 where an inverter chain with a growth factor of $h$ is represented. To reduce the complexity, LL inverters with an identical input signal can be merged in order to simplify the final circuit. To limit the current driven by each inverter and to improve the decoupling, the LL inverters are split into several parts which are distributed all along the power line.

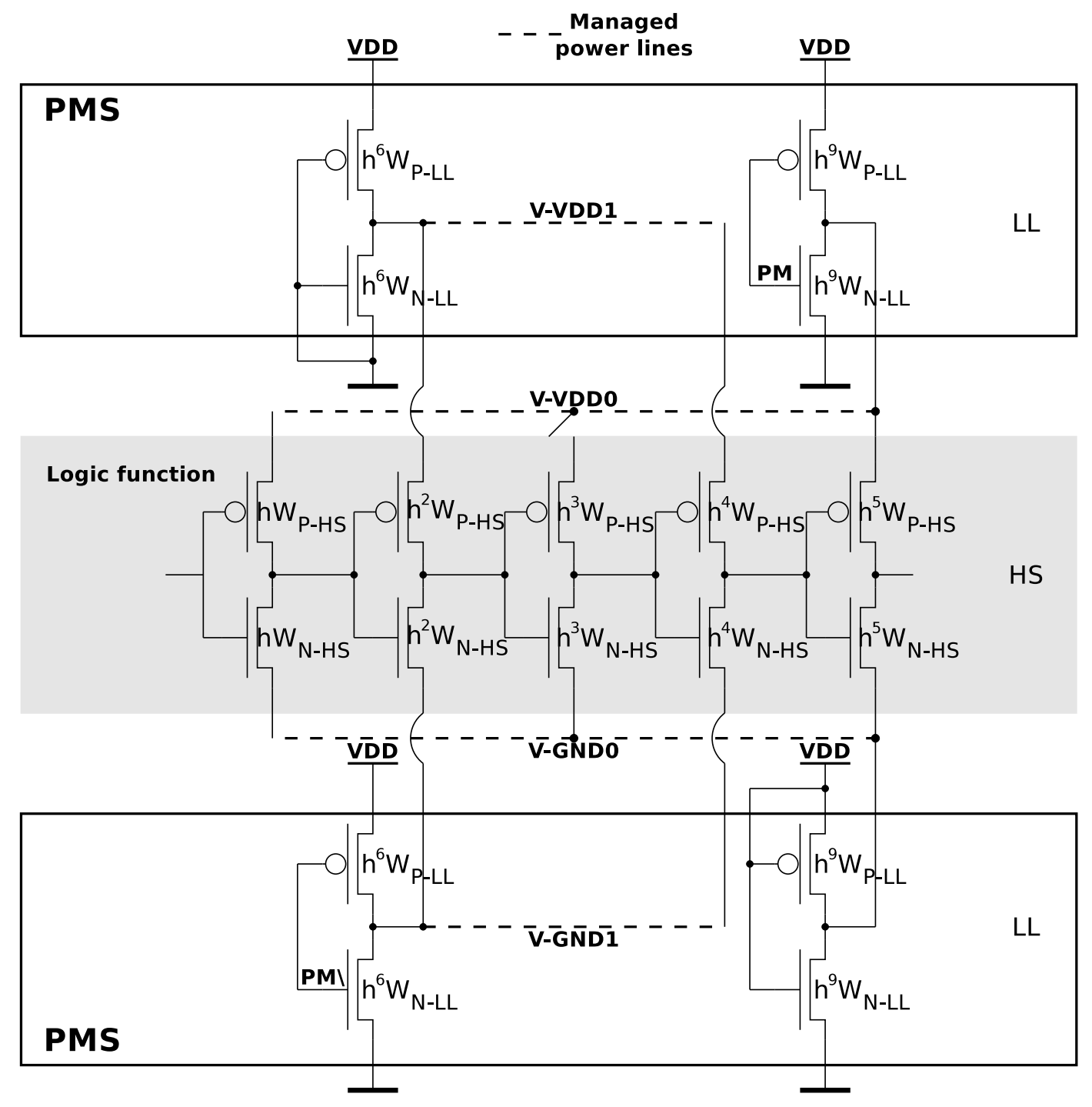

Figure 6: Inverter chain with MPS. 


\section{B) Edge combiner}

The edge combiner used has to generate the baseband pulse required by the filter excitation technique when a rising edge appears on CK. Then, CK is used to set PM and $\mathrm{PM} \backslash$ to GND and VDD respectively and then to control the MPS. As shown in Fig. 7, $\mathrm{CK}$ is delayed (CKd) before being provided to the edge combiner in order to ensure that the circuits are turned on when the signal is applied to the input. CKd is propagated through a delay line. Two consecutive edges ( $\mathrm{A}$ and $\mathrm{B} \backslash$ ) are combined to produce the baseband pulse needed to excite the filter. CKd is further delayed to produce the signal (CKend) which is used by the power manager to shut down the power lines. The edge combiner uses only CMOS logic gates implemented with HS transistors and driven by the MPS. The baseband pulse is produced by using a simple CMOS NOR gate based on inverters designed as described above. A driver based on an inverter string is inserted at the output to match the small transistors $(\mathrm{W}=10 \mu \mathrm{m})$ used in the NOR gate with the large ones used in the filter driver.

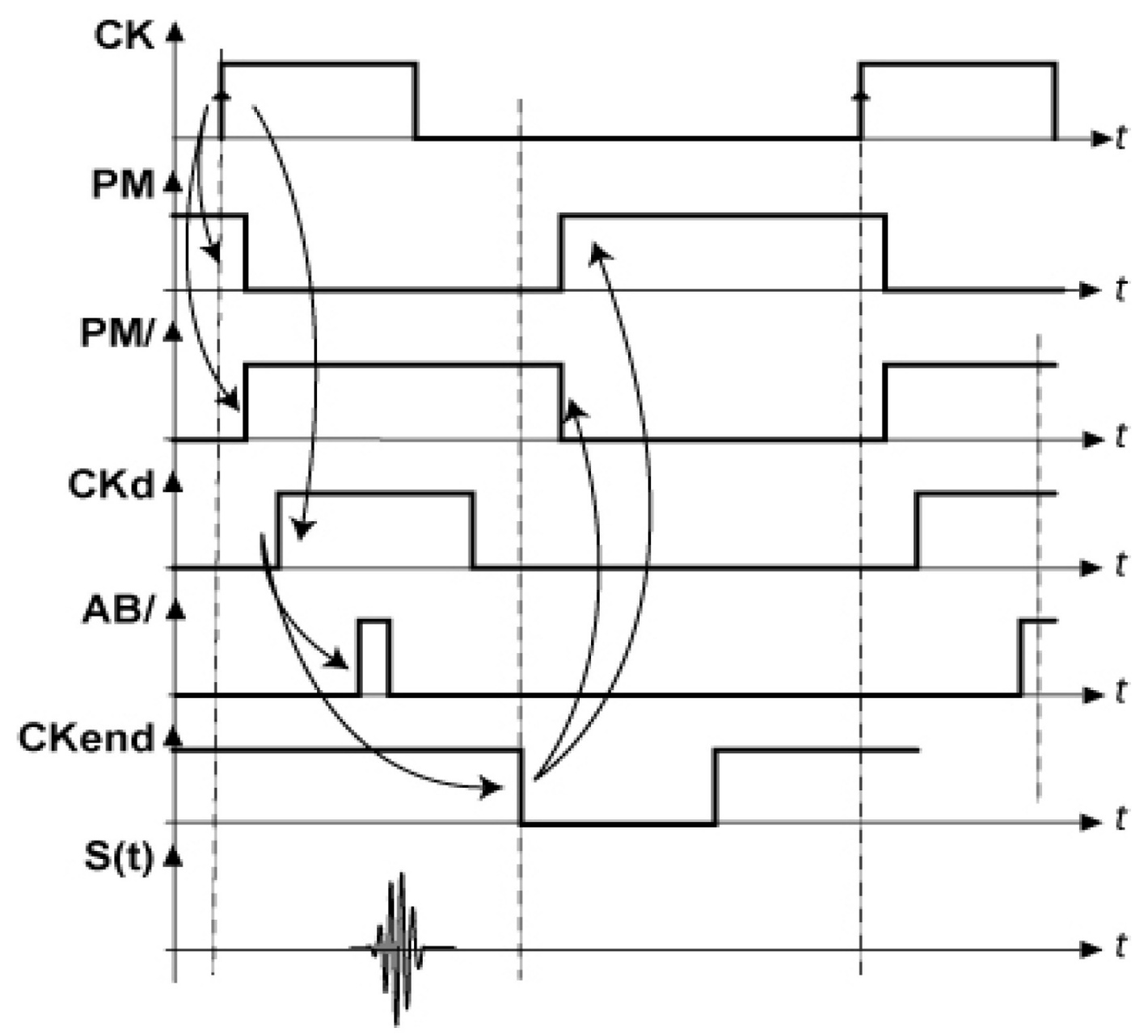

Figure 7: Main signal chronograms. 


\section{C) Band pass filter and filter driver}

The band pass filter is a Bessel-Thompson filter. This filter is chosen because a third order is sufficient to match the FCC mask. Low order reduces the number of inductors needed and then reduces the loss in the filter which finally maximizes the $E_{P}$. The filter must be carefully designed and the interconnected wires must be shortened during the layout realization to limit loss. The parasitic capacitances of the inductors must be compensated to avoid the degradation of the filter impulse response and to ensure that the pulse complies with the FCC mask. Among the different possible filter structures, the one chosen offers many advantages. The first resonator (L-C1) can be used to bias the filter driver. Cs achieves a DC isolation and C2 can be used to compensate the pad capacitance. Moreover, Cp can be reduced to compensate the parasitic capacitance of Lp. $\mathrm{Cp}$ and $\mathrm{Cs}$ can be reduced to compensate that one of Ls and $\mathrm{C} 1$ can be reduced to compensate both the output capacitance of the filter driver and the parasitic capacitance of L. The filter is driven in a current mode in order to achieve a pulse magnitude greater than the supply voltage on the $50 \Omega$ input impedance of the filter. The driver is a class $\mathrm{C}$ amplifier to avoid power consumption when no pulse is generated. To further reduce the leakage, a LL transistor is used. The width of the transistor M1 is tuned to maximize the energy efficiency given by (3) which leads to a value of $560 \mu \mathrm{m}$. The main parameters of the filter design are summarized in Table 1.

Table 1: Main design parameters summary.

\begin{tabular}{llllllll}
\hline $\begin{array}{l}\mathrm{L} \\
(\mathrm{pH})\end{array}$ & $\begin{array}{l}\mathrm{C} 1 \\
(\mathrm{fF})\end{array}$ & $\begin{array}{l}\mathrm{Cs} \\
(\mathrm{fF})\end{array}$ & $\begin{array}{l}\mathrm{Lp} \\
(\mathrm{nH})\end{array}$ & $\begin{array}{l}\mathrm{Cp} \\
(\mathrm{fF})\end{array}$ & $\begin{array}{l}\mathrm{Ls} \\
(\mathrm{nH})\end{array}$ & $\begin{array}{l}\mathrm{C} 2 \\
(\mathrm{fF})\end{array}$ & $\begin{array}{l}\mathrm{W}_{M 1} \\
(\mu \mathrm{m})\end{array}$ \\
\hline 326 & 486 & 584 & 1.08 & 338 & 1.05 & 32 & 560 \\
\hline
\end{tabular}

\section{MEASUREMENT RESULTS}

The pulse generator has been designed with a $0.13 \mu \mathrm{m}$ standard CMOS technology from ST Microelectronics. The die is shown in Fig. 8 and its area is $0.56 \mathrm{~mm}^{2}$. The measured time and normalized frequency responses of the generated pulse are given in Fig. 9. The $-10 \mathrm{~dB}$ bandwidth $\left(\mathrm{BW}_{-10 \mathrm{~dB}}\right)$ is $5.22 \mathrm{GHz}$ and is centred on $6.25 \mathrm{GHz}$. The very wide bandwidth of the pulse leads to a very short time duration equal to $0.6 n s$ which is a large benefit for localization precision but a major drawback for the emitted energy. The pulse magnitude is $2 \mathrm{Vpp}$ and produces high pulse energy although the duration of the pulse is short. The measured energy of the emitted pulse is $2.15 \mathrm{pJ}$ whereas the approximation given by (7) is $2.37 \mathrm{pJ}$ which confirm the accuracy of this approximation. 


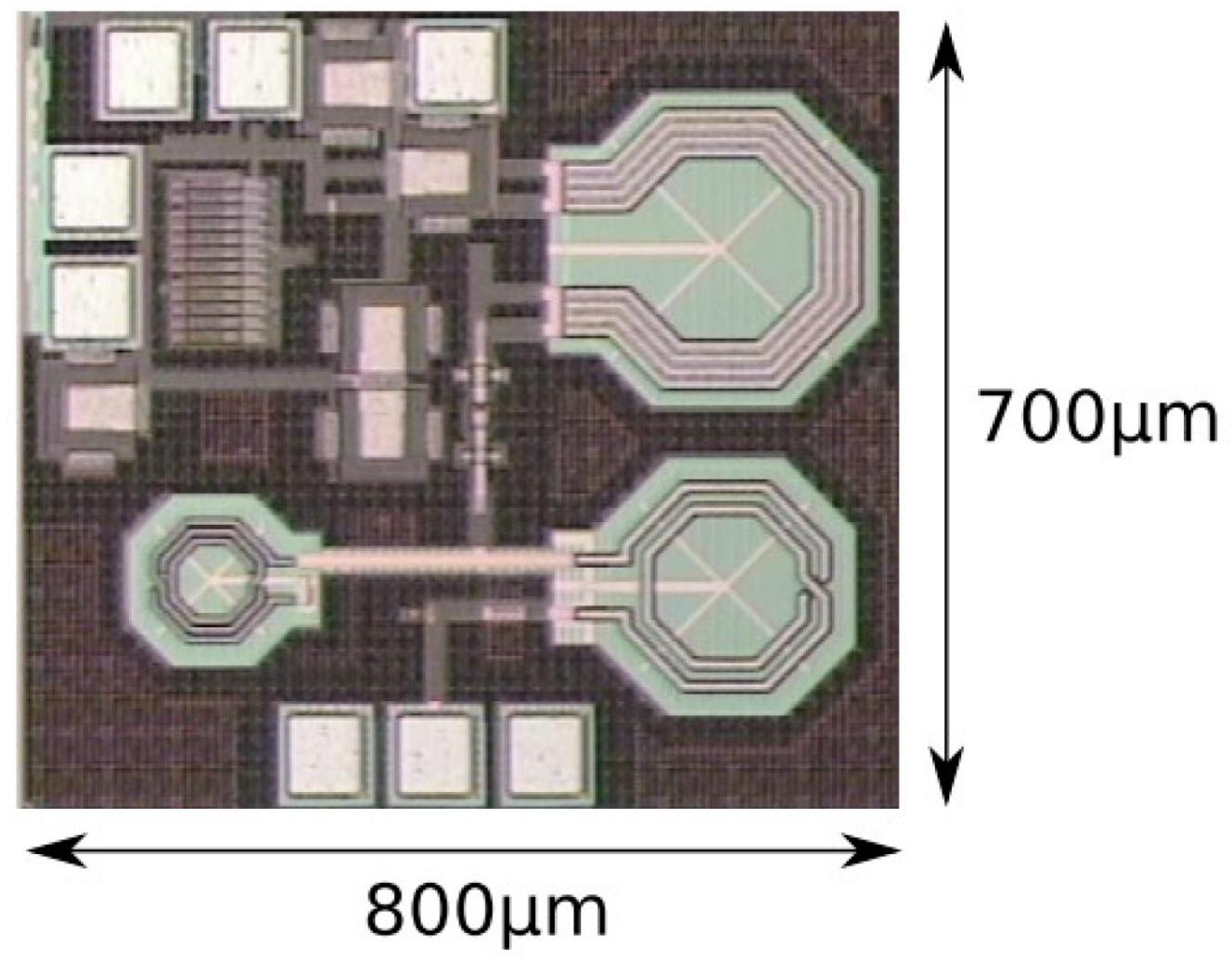

Figure 8: Die photograph of the proposed pulse generator. 


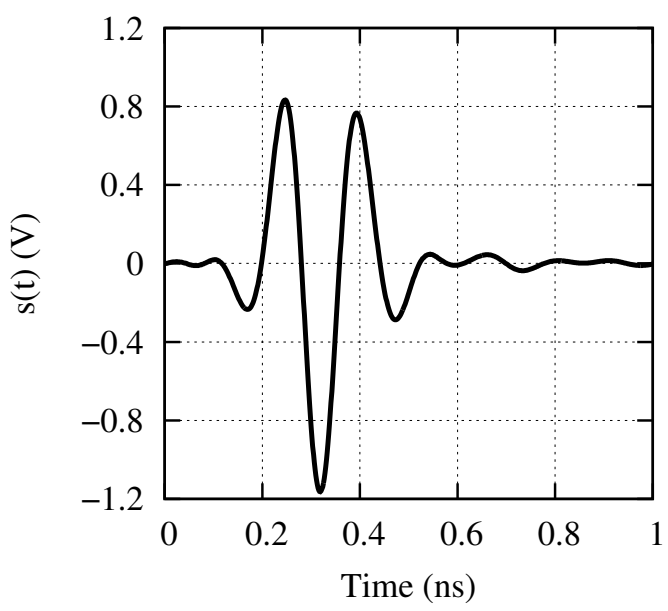

(a)

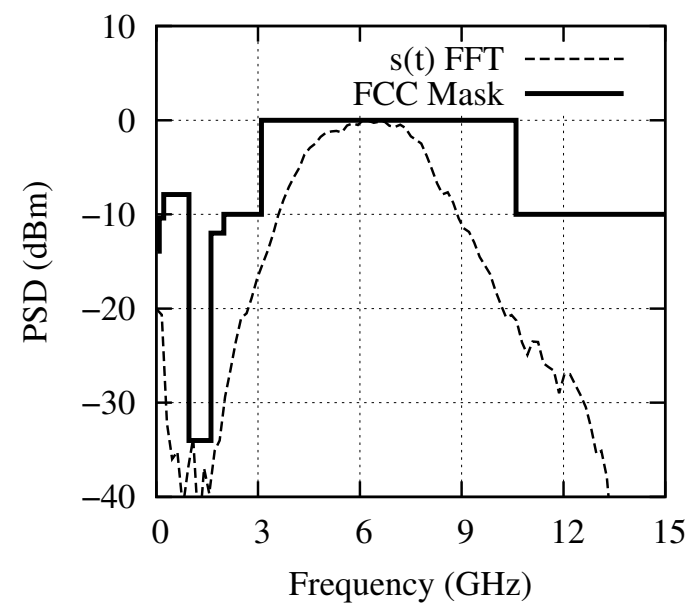

(b)

Figure 9: Measurement of the time response (a) and the frequency response (b).

The static leakage current is equal to $3.26 \mu \mathrm{A}$ which leads to a power leakage $P_{0 \mathrm{~Hz}}$ of $3.91 \mu \mathrm{W}$ for a voltage supply of $1.2 \mathrm{~V}$. Half of the power leakage is due to the filter driver. The measured power consumption is plotted for different PRF in Fig. 10 and is identical to the one obtained (2). The performances are compared with previous works in Fig. 10. The power consumption is only $3.98 \mu \mathrm{W} @ 1 \mathrm{kbs}^{-1}$ and $10.7 \mu \mathrm{W} @ 100 \mathrm{kbs}^{-1}$ which is well suited for ultra low powered applications. The value of $E_{A C}$ is extracted from this measurement and is 68pJ. Most of the consumed dynamic energy is due to the inverter string needed to match the edge combiner with the filter driver. In Fig. 11, the efficiency is plotted as a function of the PRF as introduced in (3) and is compared to previously published works which are summarized in Table 2. The pulse generator also exhibits good efficiency at low rates $\left(0.06 \% @ 1 \mathrm{kbs}^{-1}\right.$ and $\left.2.22 \% @ 100 \mathrm{kbs}^{-1}\right)$. 
Table 2: Performance summary of the proposed pulse generator and comparison with previous works.

\begin{tabular}{lllllllllll}
\hline Ref. & $\begin{array}{l}\text { Vpp } \\
(\mathrm{V})\end{array}$ & $\begin{array}{l}\text { VDD } \\
(\mathrm{V})\end{array}$ & $\begin{array}{l}\text { Width } \\
(\mathrm{ns})\end{array}$ & $\begin{array}{l}\mathrm{BW} \\
(-10 \mathrm{~dB})\end{array}$ & $\begin{array}{l}\mathrm{f}_{M} \\
(\mathrm{GHz})\end{array}$ & $\begin{array}{l}P_{0 H z} \\
(\mu \mathrm{W})\end{array}$ & $\begin{array}{l}E_{A C} \\
(\mathrm{pJ})\end{array}$ & $\begin{array}{l}E_{P} \\
(\mathrm{pJ})\end{array}$ & $\begin{array}{l}\text { Area } \\
\left(\mathrm{mm}^{2}\right)\end{array}$ & $\begin{array}{l}\text { CMOS } \\
(\mathrm{nm})\end{array}$ \\
\hline$[2]$ & 0.61 & 0.9 & 2.0 & $0.5 \mathrm{GHz}$ & $2.9-3.8$ & 184 & 65 & $1.60^{2}$ & $0.60($ die $)$ & 90 \\
\hline$[5]$ & 0.65 & 1.0 & 3.0 & $0.5 \mathrm{GHz}$ & $3.5-4.5$ & 96 & 47 & $3.17^{1}$ & $0.08($ core $)$ & 90 \\
\hline$[6]$ & 0.45 & 1.0 & 3.0 & $1.0 \mathrm{GHz}$ & $3.5-4.5$ & 5 & 30 & $0.54^{2}$ & $0.42($ core $)$ & 90 \\
\hline$[7]$ & 1.42 & 1.2 & 0.5 & $6.8 \mathrm{GHz}$ & 7.3 & 3200 & 6.4 & $0.64^{2}$ & $0.54($ die $)$ & 130 \\
\hline$[9]$ & 0.16 & 1.5 & 3.5 & $0.5 \mathrm{GHz}$ & 3.8 & 3900 & 17 & $0.11^{2}$ & $0.66($ die $)$ & 180 \\
\hline$[16]$ & 0.60 & 1.0 & 2.5 & $0.5 \mathrm{GHz}$ & $2.1-5.7$ & 124 & 17 & $1.75^{2}$ & $0.07($ core $)$ & 90 \\
\hline$[17]$ & 0.09 & 0.9 & 3.5 & $0.5 \mathrm{GHz}$ & $3.5-4.5$ & 170 & 12 & $0.03^{2}$ & $0.03($ core $)$ & 65 \\
\hline$[18]$ & 0.45 & 0.9 & 2.4 & $0.5 \mathrm{GHz}$ & $3.5-4.5$ & 2.8 & 29 & $1.20^{1}$ & $1.30($ die $)$ & 90 \\
\hline This work & 2.00 & 1.2 & 0.6 & $5.2 \mathrm{GHz}$ & 6.3 & 3.91 & 68 & $2.37^{2}$ & $0.56($ die $)$ & 130 \\
\hline
\end{tabular}

\footnotetext{
${ }^{1}$ Computed with (6)

${ }^{2}$ Computed with (7)
} 


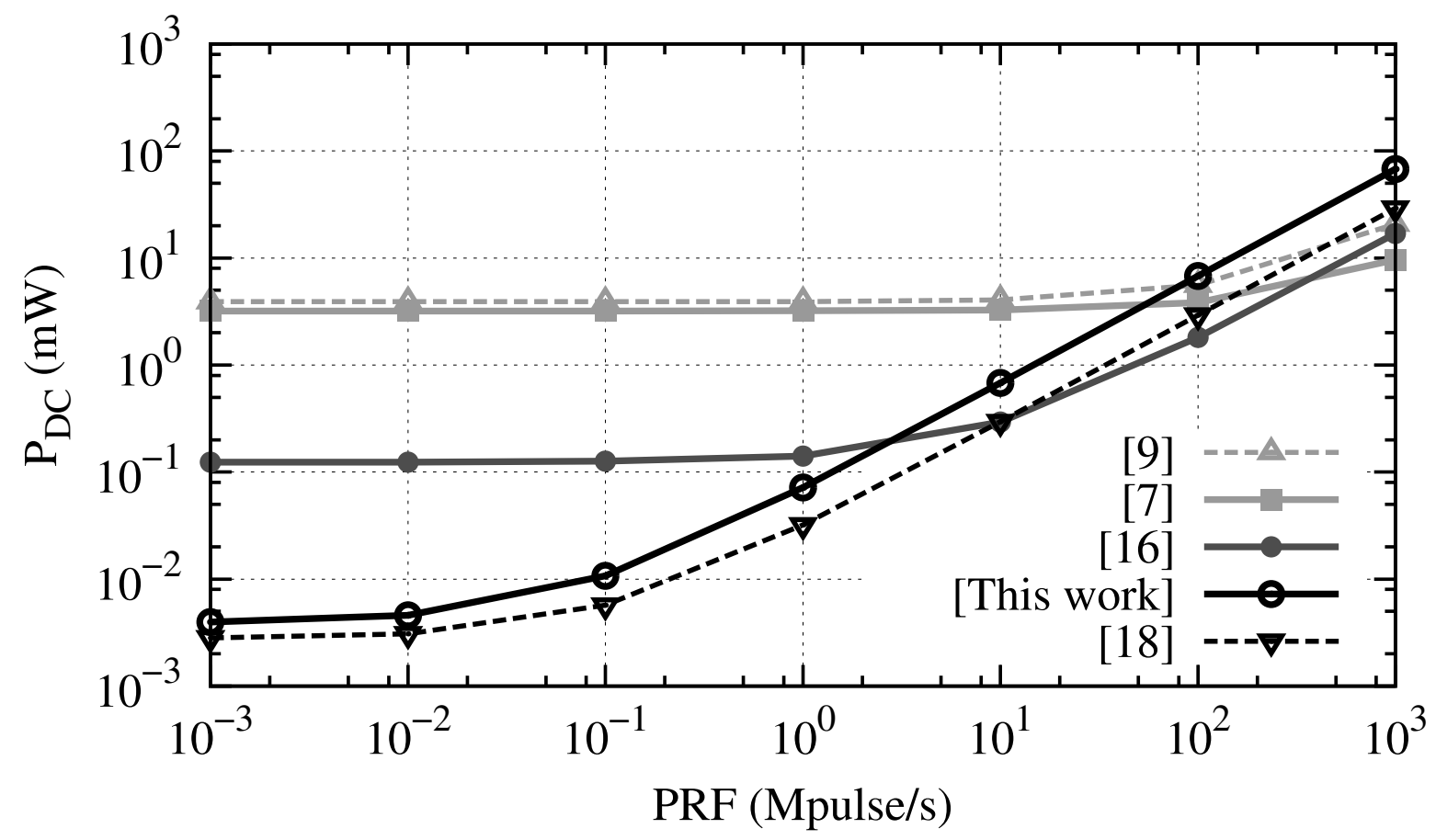

Figure 10: Measured power consumption as a function of the PRF. 


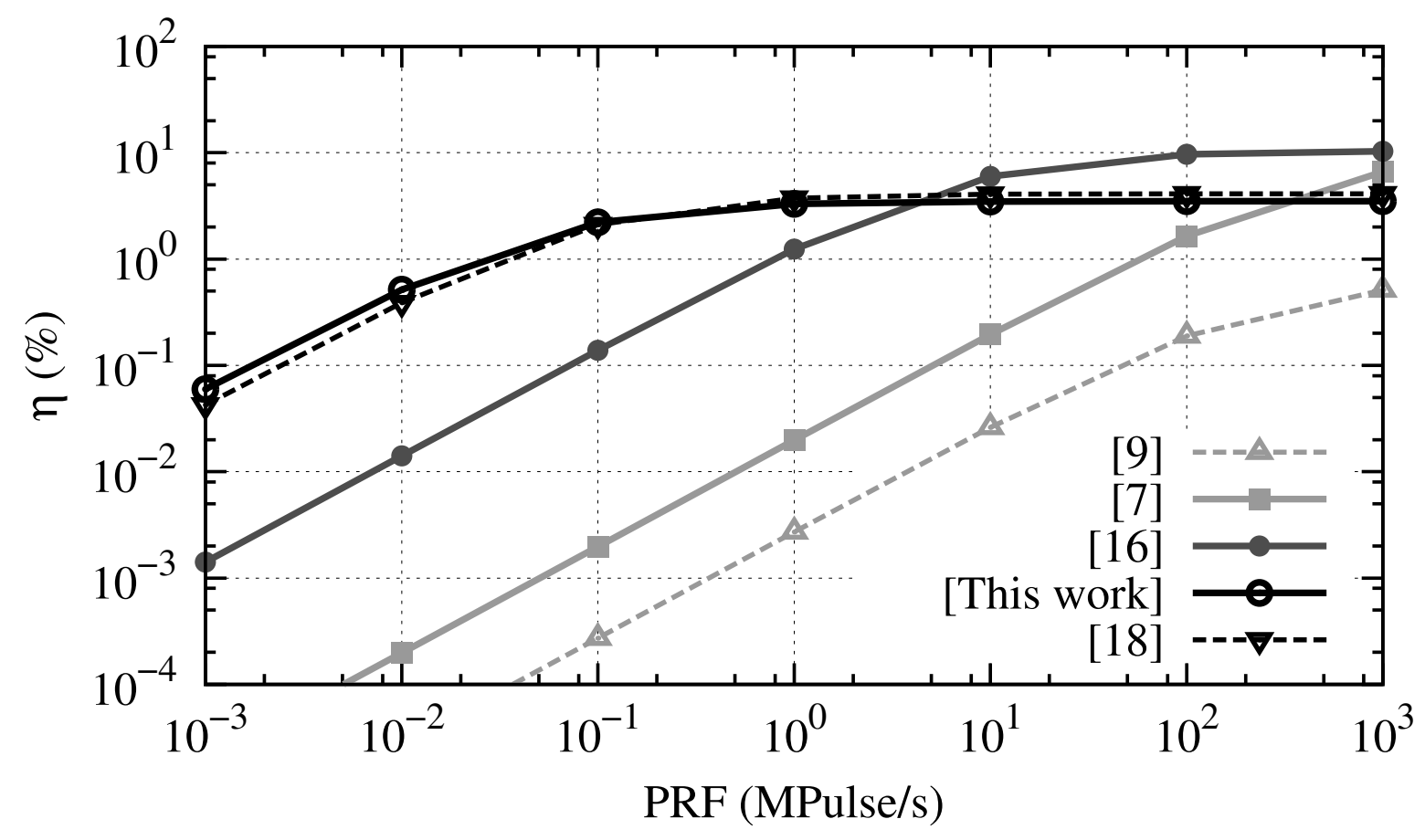

Figure 11: Estimated efficiency as a function of the PRF.

\section{CONCLUSION}

The design of an ultra low power and high efficient pulse generator has been presented. The topology has been carefully chosen to achieve good performances at low rates. It is demonstrated that the filter excitation technique can generate very short $2.15 \mathrm{pJ}$ pulses which can be helpful for high precision location applications. Associated to a power management technique which reduces leakage current, this topology demonstrates also low power capabilities $\left(3.98 \mu \mathrm{W} @ 10 \mathrm{kbs}^{-1}\right)$ and could be used in ultra low power systems.

\section{REFERENCES}

[1] Karthaus, U.; Fischer, M.: Fully integrated passive UHF RFID transponder IC with 16.7W minimum RF input power. IEEE Journal of Solid-State Circuits, 2003, 1602-1608.

[2] Crepaldi, M.; Li, C.; Dronson, K.; Fernandes, J.; Kinget, P.: An Ultra-Low-Power interference-robust IR-UWB transceiver chipset using self-synchronizing OOK modulation. IEEE International Solid-State Circuits Conference (ISSCC), 2010, 226-227.

[3] Guidi, F.; Dardari, D.; Roblin, C.; Sibille, A.: Backscatter Communication Using Ultrawide Bandwidth Signals for RFID Applications. The Internet of Things, 2010, 251-261.

[4] Dehaese, N.; Battista, M.; Vauche, R.; Bourdel, S.; Gaubert, J.; Fourquin, O.; et al.: Lowpower CMOS energy detector for noncoherent impulse-radio UWB receivers. IEEE International Conference on Ultra-Wideband (ICUWB), 2010, 1-4. 
[5] Wentzloff, DD.; Chandrakasan, A.: A 47pJ/pulse 3.1-to-5GHz All-Digital UWB Transmitter in 90nm CMOS. IEEE International Solid-State Circuits Conference (ISSCC), 2007, 118-591.

[6] Dokania, R.; Wang, X.; Tallur, S.; Dorta-Quinones, C.; Apsel, A.: An Ultralow-Power DualBand UWB Impulse Radio. IEEE Transactions on Circuits and Systems II, 2010, 541-545.

[7] Bourdel, S.; Bachelet, Y.; Gaubert, J.; Vauche, R.; Fourquin, O.; Dehaese, N.; et al.: A 9-pJ/Pulse 1.42-Vpp OOK CMOS UWB Pulse Generator for the 3.1-10.6GHz FCC Band. IEEE Transactions on Microwave Theory and Techniques, 2010, 65-73.

[8] Sim, S.; Kim, DW.; Hong, S.: A CMOS UWB Pulse Generator for 6-10 GHz Applications. IEEE Microwave and Wireless Components Letters, 2009, 83-85.

[9] Phan, AT.; Lee, J.; Krizhanovskii, V.; Le, Q.; Han, SK.; Lee, SG.: Energy-Efficient LowComplexity CMOS Pulse Generator for Multiband UWB Impulse Radio. IEEE Transactions on Circuits and Systems I: Regular Papers, 2008, 3552-3563.

[10] Barras, D.; Ellinger, F.; Jackel, H.; Hirt, W.: Low-power ultra-wideband wavelets generator with fast start-up circuit. IEEE Transactions on Microwave Theory and Techniques, 2006, $2138-2145$.

[11] Bourdel, S.; Gaubert, J.; Fourquin, O.; Vauche, R.; Dehaese, N.: CMOS UWB pulse generator co-designed with package transition. IEEE Radio Frequency Integrated Circuits Symposium, 2009. RFIC 2009, 2009, 539-542.

[12] Keshavarzi, A.; Ma, S.; Narendra, S.; Bloechel, B.; Mistry, K.; Ghani, T.; et al.: Effectiveness of reverse body bias for leakage control in scaled dual Vt CMOS ICs. Low Power Electronics and Design, International Symposium on, 2001., 2001, 207-212.

[13] Assaderaghi, F.; Parke, S.; Sinitsky, D.; Bokor, J.; Ko, PK.; Hu, C.: A dynamic threshold voltage MOSFET (DTMOS) for very low voltage operation. IEEE Electron Device Letters, $1994,510-512$.

[14] Wei, L.; Chen, Z.; Roy, K.; Johnson, MC.; Ye, Y.; De, VK.: Design and optimization of dual-threshold circuits for low-voltage low-power applications. IEEE Transactions on Very Large Scale Integration (VLSI) Systems, 1999, 16-24.

[15] Sakurai, T.; Newton, A.: Alpha-power law MOSFET model and its applications to CMOS inverter delay and other formulas. IEEE Journal of Solid-State Circuits, 1990, 584-594.

[16] Mercier, PP.; Daly, DC.; Chandrakasan, A.: An Energy-Efficient All-Digital UWB Transmitter Employing Dual Capacitively-Coupled Pulse-Shaping Drivers. IEEE Journal of SolidState Circuits, 2009, 1679-1688.

[17] Park, Y.; Wentzloff, DD.: An All-Digital 12 pJ/Pulse IR-UWB Transmitter Synthesized From a Standard Cell Library. IEEE Journal of Solid-State Circuits, 2011, 1147-1157.

[18] Dokania, RK.; Wang, XY.; Dorta-Quinones, CI.; Godycki, W.; Tallur, SG.; Apsel, A.: A $6 \mathrm{uW}, 100 \mathrm{kbps}, 3-5 \mathrm{GHz}$, UWB impulse radio transmitter. ACM/IEEE International Symposium on Low-Power Electronics and Design (ISLPED), 2010, 91-94. 


\section{Bibliographies}

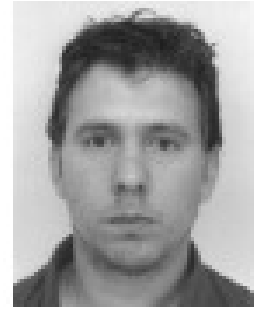

Remy Vauche got into preparation for the competitive entrance examinations to French Engineering Schools, Metz, France, in 2003. He received the M.Eng degree in microelectronics and telecommunication from Polytech' Marseille, and the M.S. degree in microelectronics and nanoelectronics from Aix-Marseille University, Marseille France, in 2008. $\mathrm{He}$ received the Ph.D. degree in microelectronics from the University of Provence, Aix-Marseille I, France, in 2011. From 2011 to 2014, he was an assistant professor in the ISEN french engineering school, Toulon, France. Since 2014, he is now an assistant professor of the Aix-Marseille University, Marseille, France, and a member of the Integrated Circuits Design Team from the Provence Nanosciences Microelectronics and Materials Laboratory (IM2NP), Marseille, France. His current field of research is in the design of UWB pulse generators for low-cost applications.

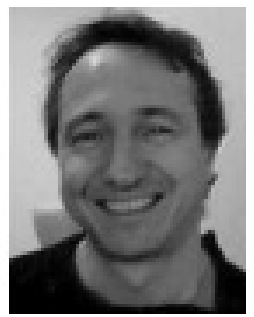

Sylvain Bourdel received the Ph.D. in microelectronics from the National Institute of Applied Science (INSA) of Toulouse in 2000. He was with the LAAS laboratory of Toulouse where he was involved on radiofrequency systems modelling and he was particularly focused on spread spectrum techniques applied to $2.45 \mathrm{GHz}$ transceivers. In 2002 he joined the IMNP in Marseille where he headed with Pr H. Barthélemy the Integrated Circuit Design Team of the IM2NP. He joined in 2013 the Grenoble-INP as a full Professor where he works at the IMEPLAHC laboratory. He works in CMOS RF IC design and integration. He particularly focus on low cost applications including RFID, UWB and narrow band systems. His area of interest also includes system level specifications, system packaging and interconnections.

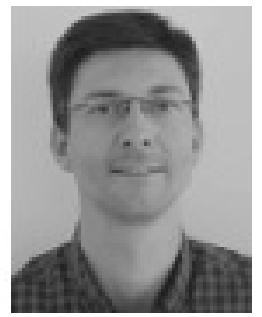

Nicolas Dehaese received the M.S. degree from the ISEN engineering school, Lille, France, in 2002 and the Ph.D. degree in electronics from the University of Provence, AixMarseille I, France, in 2005. Since 2006, he is an assistant professor in the Integrated Circuits Design Team from the Provence Nanosciences Micro-electronics and Materials Laboratory (IM2NP), Marseille, France. His current field of research is in the design of analog/RF CMOS integrated circuits and system level specifications for low-cost applications including narrow band $(2.4 \mathrm{GHz})$ and Ultra Wideband (3.1-10.6GHz) systems. 
Jean Gaubert received the M.S. and the Ph.D. degrees in applied physics from Paul Sabatier University, Toulouse, France, in 1985, and 1988, respectively. From 1989 to 2001 he was an Assistant Professor at the Ecole Nationale Supérieure de l'Electronique et de ses Applications, Cergy-Pontoise, France, where he was involved with high-speed GaAs and InP bipolar devices modelling. In 2001, he joined the University of Provence, Marseille, France, and the Institut Matériaux Microélectronique Nanosciences de Provence (IM2NP). His research focuses on the design and integration of RF/Microwave CMOS integrated-circuits and systems for wireless communications. He has published more than 60 refereed journal and conference papers.

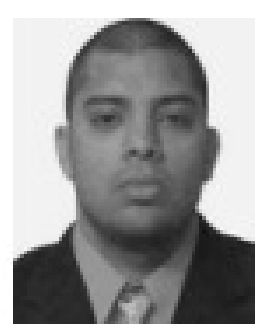

Oswaldo Ramos Sparrow was born in Lima, Peru, in 1984. He was studied engineer electronic at Ricardo Palma University in Lima-Peru. He received the M. Eng degree in microelectronics and telecommunication from Polytechnique Marseille, France in 2010 and the M.S. in micro-electronics and nanoelectronics from Aix-Marseille University, Marseille France, in 2011. He is currently working towards the Ph.D. degree at the University of Nice-Sophia Antipolis, France. His current research interests include UWB radio transceiver modeling and design in 0.13lm CMOS technology for low-power and low-cost applications.

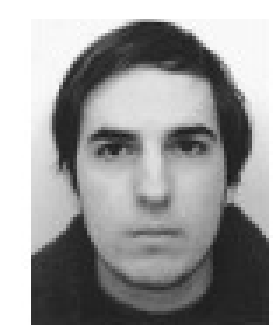

Eloi Muhr was born in Reims, France, in 1989. He received the M.S. in microelectronics and nanoelectronics from Aix-Marseille University, Marseille France, in 2012. He is currently a Ph.D. student of Aix Marseille University with the IM2NP laboratory. His current research interests include CMOS UWB radio transceiver design and programmable UWB system.

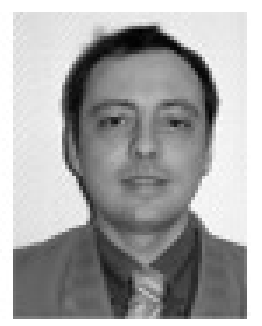

Herve Barthelemy received the MSc degree in Electrical Engineering in 1992 and the Ph.D. degree in Electronics from the University of Paris XI Orsay, France in 1996. In 2002 he received the HDR degree from the University of Provence, Aix-Marseille I, France. From 1996 
to 2000 he was an Assistant Professor at the Institut Supérieur dElectronique de la Méditerranée (ISEN) in Toulon, France. In 2000 he joined the University of Provence where is has been a full Professor since 2005. In 2007 He joined the University of Sud-Toulon-Var. Since 2005 he headed the Integrated Circuits Design Team at the IM2NP. The team has 12 researchers and Ph.D. students involved in several research projects with industry. His research interests are mainly in the design of radiofrequency analog integrated circuits. He authored and co-authored multiple publications in international journals and conference proceeding.

\section{List of figures and tables}

Fig. 1. Instantaneous consumed power.

Fig. 2. Power consumption of several published pulse generators.

Fig. 3. Energy efficiency of several published pulse generators.

Fig. 4. Proposed pulse generator principle.

Fig. 5. Inverter set to 0 (a) and set to 1 (b) in the idle state with its associated Managed Power Supply (MPS).

Fig. 6. Inverter chain with MPS.

Fig. 7. Main signal chronograms.

Fig. 8. Die photograph of the proposed pulse generator.

Fig. 9. Measurement of the time response (a) and the frequency response (b).

Fig. 10. Measured power consumption as a function of the PRF.

Fig. 11. Estimated efficiency as a function of the PRF.

Table 1. Main design parameters summary.

Table 2. Performance summary of the proposed pulse generator and comparison with previous works. 